\title{
Pupil's Beliefs about the Transformations of Energy in Three Countries (Canada, France and Morocco)
}

\author{
Abdeljalil Métioui ${ }^{1{ }^{1 *},}$ Mireille Baulu MacWillie ${ }^{2}$ \\ ${ }^{1}$ Université du Québec à Montréal, Montréal Case postal 8888, succursale Centre-ville, Montréal (Québec) H3C 3P8 Canada \\ ${ }^{2}$ Université Sainte-Anne 1695, Route 1, Pointe-de- l'Église (Nouvelle-Écosse), BOW 1MO Canada
}

Copyright (C) 2015 Horizon Research Publishing All rights reserved.

\begin{abstract}
A qualitative research approach was chosen to analyse the conceptions of pupils attending elementary school from Canada $(\mathrm{N}=135)$, France $(\mathrm{N}=30)$ and Morocco $(\mathrm{N}=92)$ between 10 and 12 years of age. Their conceptions were identified while being mobilised on energy transformations during the working of a simple electric circuit made of a battery, a bulb and electric wires: light, thermal, electrical and chemical. With paper and pencil, they completed a questionnaire made up of six questions during a forty-five minute period. The analysis of the data of the experimentation demonstrates that the majority of the conceptions identified are naïve compared to those constructed by the scientists. It also shows that their conceptions are similar in spite of the different cultures. The results confirm the findings of the international community of researchers in didactics of sciences regarding the universality of children's conceptions about the working of simple electrical circuits. These findings have implications on teacher training, science teaching and learning in a multiple cultural environment.
\end{abstract}

Keywords Pupils, Primary School, Conception, Transformation, Energy, Electrical Circuit

\section{Introduction}

This research is part of studies related to the "universality" or the "ethnoncentricity" of pupils conceptions about scientific phenomena before these phenomena have been taught to them. In the case of the universality of these conceptions, several researchers have demonstrated that they are developed by the children of different cultures and different countries in their interactions within the physical and social environment. Such conceptions are similar in the case of force, gravity, shape of the erth and the appearance of day and night $[1 ; 2 ; 3 ; 4]$. For example, McCloskey [1] and Viennot [2] establish a certain parallelism between the children's conceptions (and adult novices) about the notion of force and the medieval impetus theory developed by
Buridan who proposed that objects are moved by an internal force or impetus and that this impetus gradually disappears over time and causes the objects to reduce their speed and eventually stop. In the case of the notions of space, time and speed, children associate speed either with time ("Go faster, we only have two minutes left") or distance ("Go faster, we have a long way to go") $[5 ; 6 ; 7]$. As for vision and light, most pupils see light as a source (an electrical bulb), an effect (a spot of light) or a state (lightning) and refer to a combination of two or three elements (the source of the light, the eye, and the object) to explain the phenomenon of vision $[8 ; 9 ; 10]$. For the notions of heat and temperature, the pupils share the same conceptions, such as: "Heat and cold are inherent properties of objects."; "Cold is not the absence of heat but rather a distinct substance."; "Heat and cold flow and have a definite physical location."; "Heat and cold accumulate and can be contained." $[11 ; 12 ; 13]$ Children consider heat as a material substance which, for example, goes through a space under a door. They confuse heat and temperature: heat is a measure of temperature. These naive conceptions generally are the result of common language. Examples of these are as follows: "Close the window and keep the heat in", "Keep the cold out". When referring to the origin of the material substance conception of heat, Erickson and Tiberghien [14] suggest two types of interpretations, one that goes back to the tenants of the caloric theory which prevailed at the end of the XV111th century and a second one which refers to common sense: "We know, however, that the notion of heat was more closely defined in the caloric theory than in its present every day meaning. Others argue that there is a natural tendency to describe our common sense world in metaphorical terms wherein cause and effect relationships are seen in terms of interactions between types of matter"'(p. 53).

Finally, on the question of matter, children interpret the mixture of substances in terms of fractioning (seeds, particles, little balls, droplets) and they do not attribute any invariant character between these little parts $[15 ; 16]$. Similar to the work of Piaget and Inhelder [17] on child atomism, Reiner et al. [18] put forward the following explanation: "The corpuscular explanation is based on the projection of 
the macroscopic view, such that the corpuscular elements are treated as small objects." Following the work of T. K. Au [19] and of Osborne and Schollum [20], they also note the absence of a conception of discontinuous matter for children. For children there is matter between corpuscles: "This corpuscular notion is often coupled with a view of substance as continuous, such that students deny the existence of space between particles, saying that space is filled with dust, germs, air, other gases, and so forth." Also, Piaget and Inhelder [17] notice a certain parallelism between child atomism and the notion developed by the Greeks on the process of the subdivision of matter.

How does one explain these similarities in spite of the differences in cultures and languages? Vosniadou [4] explains this universality of conceptions by the cognitive mechanism of children that results from the interaction of their mental structure and the object of knowledge. "If initial concept result mainly from an interaction of the human perceptual/cognitive system with information coming from the observed world (before the children are exposed to culture-specific information), one should expect that these concepts should be universal because the humain/cognitive system and many aspects of the observed world are universal."(p. 3). As for some notions in the field of biology such as the animal world [21], ecological concepts [22] and evolution $[23 ; 24 ; 25]$, they are not universal. For example, some teachers and parents do not agree with the teaching of the theory of evolution, as is the case in South Africa for instance [25]: "The teaching of evolution provided fertile ground for researchers trying to understand and address potential problems it may cause. Because there has been resistance from some parents and teachers about including evolution in the South African school curriculum we start by considering why scientists and educationists believe it is essential to teach evolution". (p. 38). The bibliographical research did not reveal systematic studies of the pupil's scientific conceptions from different cultures and languages in primary school. The present research was developed to identify the conceptions of pupils from three countries about energy transformations in the case of the functioning of a simple electric circuit.

Pupils bring their naive notions about natural phenomena with them as they enter the classroom, which particularly in science classes, may conflict with the concepts being presented [26; 27]. Contrary to intuitive knowledge, scientific knowledge contradicts common experience, opposes commonly held opinions, and departs from ordinary conditions of observation [28]. This mismatch between what pupils believe and the scientific concepts being presented has the effect that pupils understand differently the ideas being presented to them. Furthermore, it is difficult to know if the misunderstandings about a scientific concept are the same or differ for each pupil. The issue is particularly important for the teaching of science in multicultural and international classes where the notions that the students bring with them may vary considerably. To overcome these obstacles to learning, some scholars involved in the teaching of sciences have suggested developing strategies that take into account the conceptions of the pupils. Bachelard [28] argued that, contrary to intuitive knowledge, scientific knowledge contradicts common experience, opposes opinion, departs from ordinary conditions of observation and manipulates the variables. The question is important in the context of multicultural classes and in an international context of didactics of sciences. This study is part of the open and well documented question of the universality or the ethnocentricity of scientific conceptions $[29 ; 30 ; 31 ; 32]$. To better understand this question, this study looks at the conceptions of pupils coming from three different countries, cultures and continents. These conceptions relate to energy transformations that underlie the functioning of a simple electric circuit made of a battery, a bulb and two electric wires for the electrical connection. These transformations involve chemical, electrical, light and thermal energy. The results are examined in light of existing studies and on learning scientific concepts in primary school. In the following section, the question of universality and ethnocentricity will be presented in the case of electrical circuits which are the central point of the present study.

\section{Studies on Electrical Circuits}

The study of simple electric circuits has already been the subject of research evaluating the degree of conformity between pupils' conceptions and scientific ideas. There are few studies that compared systematically the representations of pupils at the primary level about electrical circuits. However comparative research has been done by Shipstone et al. [33] with pupils at the secondary level (15-17 year-old) in five countries of Europe (France, England, Netherlands, Sweden and West-Germany). In this study, the researchers have identified the conceptions of pupils having taken a course on the analysis of simple electrical circuits focusing on the concepts related to electrical current and voltage. Many conceptions identified in this comparative study are similar and some are different as noted in the following passage: "When within-country results were averaged across student groups the between-country differences on many aspects of this subject were quite small. Those electrical principles which yielded significant differences fell into two main groups, one concerned with current, flow of charge and energy, the other with voltage and its relationship to current. The consistency with which these significant differences emerged across a range of problems concerning related principles suggests that these represent real differences between the outcomes of teaching across the five countries but the causes of these differences are not yet clear. Despite the differences that have emerged, the overall impression which the results convey is of substantially the same pattern of learning difficulties across countries and the existence of an almost 'natural' coherence to these learning difficulties within cognitive structure" (p. 303) It is possible that these differences can be explained by the educational programs 
from each of the countries.

Although nonsystematic studies have been conducted at the primary level in different countries ([34]; [35]; [36]; [37]; [38], [39]) they attest to a majority of pupils constructing some conceptions in discontinuity with the scientific views when they are invited to explain the lighting of a bulb with the help of a battery. Their conceptions especially refer to (1) the attenuating model (in which the currents leaves one terminal of the battery and is partially consumed in the bulb, so that a lesser current returns to the battery), (2) the model of antagonistic currents (in which currents circulate towards the bulb from both terminals of the battery and (3) the unipolar model (in which the current leaves from the battery and arrives at the bulb; thus, the wire that goes back toward the battery is considered as superfluous or passive). From these studies, it is possible to conclude that there is universality in the conceptions characterized since no cultural reference has been detected in the answers of the pupils coming from South Africa [34], Canada [35], the United States [36], Australia [37], Turkey [38], New Zealand [39] and other countries. However, more research is necessary on the question of universality of conceptions. For example, what are the pupils' conceptions in relationship to the transformation of energy that appears in the functioning of a simple electric circuit? From the review of the literature it was not possible to identify some research on this question. The majority of the studies revolved around a simple circuit connection and its functioning in terms of "current". The purpose of the present research is to identify the conceptions of pupils from three different countries on the transformations of energy in a simple electrical circuit.

\section{Sampling}

The collection of the data has been achieved from a sampling of 257 pupils in the 5th and 6th grades (Canada) and their equivalent of the 6th year, the CM2 (France and Morocco). The pupils are between 9 and 12 years of age. The sampling in each of the countries presents itself as follows: Canada $(\mathrm{N}=135)$, Morocco $(\mathrm{N}=92)$ and France $(\mathrm{N}=30)$. Canada is represented by two distinct groups: the first $(\mathrm{N}=$ 89) comes from a region of Nova Scotia: (a) 69 pupils are from the region of Yarmouth and were registered in a French Immersion public school; the schoolchildren speak French and English. French spoken by these pupils is by and large a second language. English is largely the maternal tongue of these pupils; (b) 20 pupils came from the neighboring region of Clare, an Acadian community where the spoken language is a French linguistic variation of standard French. These children also speak English. The pupils mostly speak English at home, French being the language of teaching in the school with English as another subject taught in the program. The second group is from a Quebec public school in Montreal (N $=46$ ) where the maternal language and the language used at school are French. English is also learned at the school. In Morocco $(\mathrm{N}=92)$, they come from two French private schools in the region of Casablanca. The majority of the pupils are Moroccan and the spoken languages are Moroccan, Berber and French. Learning English is part of the school's curriculum. In France $(\mathrm{N}=30)$, the pupils are registered in two public schools of Poitiers. Their language is French and English is part of the school's curriculum. All these pupils have some knowledge on how to set an electric circuit made of a battery, a bulb and two connecting wires.

\section{Questionnaire}

The collection of the data came from a "paper-pencil" questionnaire made up of six questions: (1) let's consider a circuit constituted of a battery, a bulb and wires to make an electrical connection. If one leaves the bulb lit during a few minutes it becomes hot; according to you why does it become hot? (2) According to you, from where does the light in the bulb come? (3) According to you, is there a difference between electricity and light? (4) According to you, is there a difference between electricity and heat? (5) According to you, what is inside a battery? 6) What is electricity for you?

The questionnaire was administered by the teachers of the participating pupils. These teachers were instructed to answer the questions of the pupils for clarification, without influencing their answers. The pupils were informed that the questionnaire that they had to complete was part of a research and that their contribution was important, something that gave them pride. They also knew that at this stage, they did not have to worry about knowing if their answers were right. What was most important was to express their personal point of view. Questions 1 and 2 refer to the transformations of energy that appear in an electric circuit constituted by a battery, a bulb and connecting wires. As for the questions 3 and 4, it was to know if the pupils thought there was a difference between electric, thermal and light energies. Finally, questions 5 was used to find out the pupils point of view on what is in a battery which is a technical object that is familiar to them and question 6 was used to find out what electricity is for them.

\section{Categorization of the Answers to the Questionnaire}

The answers of the pupils were grouped for each of the countries, one question at a time. For each question, a regrouping of the answers was made in different categories, their number differing from one question to another, according to the answers given. Then, an interpretation was made of the answers identified in each of the categories in order to specify the most widely spread explanations. 


\subsection{Categorization of the Answers: Question 1}

This question served to know how the pupils explain the warming up of a bulb in an electric circuit. The data collected revealed five categories of answers as described in table 1.

The few typical answers relatively to each of these categories are reproduced fully in table 2 . They represent the pupil's complete explanation. In order to personalize information while preserving anonymity, the answers have been identified by letters followed by a number: $n_{1}$ (the number of a pupil from the Nova Scotia), $m_{1}$ (the number of a pupil from Montreal), $\mathrm{p}_{1}$ (the number of a pupil from Poitiers), $c_{1}$ (the number of a pupil from Casablanca). Each group has its own letter and each pupil its own number.
Table 1. Categories derived from question 1

\begin{tabular}{|c|c|c|c|}
\hline Cat. & Interpretation of pupils & $\%$ & $(\mathrm{a}, \mathrm{b}, \mathrm{c}, \mathrm{d})^{*}$ \\
\hline $\mathrm{C}_{1}$ & $\begin{array}{c}\text { Warming up of the filament in the } \\
\text { bulb. }\end{array}$ & 14 & $(11,33,12,12)$ \\
\hline $\mathrm{C}_{2}$ & Releasing of the heat by the light. & 10 & $(17,4,20,5)$ \\
\hline $\mathrm{C}_{3}$ & $\begin{array}{c}\text { Releasing of the heat by the hot } \\
\text { electricity. }\end{array}$ & 17 & $(10,6,30,18)$ \\
\hline $\mathrm{C}_{4}$ & $\begin{array}{c}\text { Accumulation or the passing } \\
\text { through, either of electricity, either } \\
\text { of a hot energy, either of the heat in } \\
\text { the bulb. }\end{array}$ & 21 & $(20,9,13,20)$ \\
\hline $\mathrm{C}_{5}$ & $\begin{array}{c}\text { Fuzzy, incomplete or } \\
\text { indecipherable answer. }\end{array}$ & 38 & $(44,48,25,45)$ \\
\hline
\end{tabular}

*(a, b, c, d) represent the respective percentages of the pupils of: Nova Scotia $(\mathrm{N}=89)$; Montreal $(\mathrm{N}=46)$; Poitiers $(\mathrm{N}=30)$ and Casablanca $(\mathrm{N}=$ 92)

Table 2. Answers of the pupils relatively to the question 1

\begin{tabular}{|c|c|}
\hline Subjects' codes & Advanced answers \\
\hline \multicolumn{2}{|c|}{ Category 1: Warming the filament of the bulb. } \\
\hline $\mathrm{n}_{2}$ & $\begin{array}{l}\text { "The bulb becomes hot because there is a small spiral filament and the electric current goes in this } \\
\text { filament and the electricity, it is very hot." (Nova Scotia) }\end{array}$ \\
\hline $\mathrm{m}_{10}$ & $\begin{array}{l}\text { "In the bulb there is a metal part as in a frying pan and well when it is lit, it becomes red and it is that that } \\
\text { makes the heat." (Montreal) }\end{array}$ \\
\hline $\mathrm{c}_{41}$ & $\begin{array}{l}\text { "The bulb becomes hot because the electric current hits the filament and that is the reason why it heats." } \\
\text { (Casablanca) }\end{array}$ \\
\hline $\mathrm{p}_{10}$ & "It becomes hot because of the electricity that heats the filament." (Poitiers) \\
\hline \multicolumn{2}{|c|}{ Category 2: Releasing of the heat by the light. } \\
\hline $\mathrm{n}_{10}$ & "It becomes hot because it shines really a lot, like the Sun and the Sun is hot." (Nova Scotia) \\
\hline $\mathrm{m}_{4}$ & $\begin{array}{l}\text { The light heats up the lamp and it (the heat) remains blocked to it (the bulb), becomes hot and when we } \\
\text { shut it off, the bulb becomes cold. " (Montreal) }\end{array}$ \\
\hline $\mathrm{c}_{69}$ & $\begin{array}{l}\text { "It becomes hot because light has heat. For example, if you take a magnifying glass and you put a leaf } \\
\text { under it and you do this in the sun, it will burn the leaf because the rays of the Sun are fire. " (Casablanca) }\end{array}$ \\
\hline $\mathrm{p}_{14}$ & $\begin{array}{l}\text { "The light is hot a bit like the Sun (but the Sun is not electricity). The electricity of the bulb warms up } \\
\text { because it produces a lot of energy. It is as when we run, we feel hot." (Poitiers) }\end{array}$ \\
\hline \multicolumn{2}{|c|}{ Category 3: Releasing the heat by the hot electricity. } \\
\hline $\mathrm{n}_{12}$ & "Electricity is hot when it touches something such as iron and wood, then it turns red." (Nova Scotia) \\
\hline $\mathrm{m}_{12}$ & $\begin{array}{l}\text { "Because electricity is hot. Electricity passes through the filament too long, the heat accumulates and, } \\
\text { through the bulb, the heat comes out of the bulb and warms up." (Montreal) }\end{array}$ \\
\hline $\mathrm{c}_{76}$ & "Because there is electricity in the battery and as electricity is hot, the lamp is hot." (Casablanca) \\
\hline $\mathrm{p}_{25}$ & "It becomes hot because while manufacturing electricity, electricity is already hot." (Poitiers) \\
\hline \multicolumn{2}{|c|}{ Category 4: Accumulation or passage, either of electricity, of a hot energy, or heat in the bulb. } \\
\hline $\mathrm{n}_{61}$ & $\begin{array}{l}\text { "Electricity produces heat. Only, one doesn't always feel it. An electric bulb traps the heat of electricity. } \\
\text { Besides, if one leaves a bulb lit too long, it burns. When we switch off the bulb, the heat disappears little } \\
\text { by little. " (Nova Scotia) }\end{array}$ \\
\hline $\mathrm{m}_{34}$ & $\begin{array}{l}\text { "If it remains a long time, the current that remains trapped in the bulb cannot get out anymore, so what } \\
\text { remains with the energy makes the heat." (Montreal) }\end{array}$ \\
\hline $\mathrm{c}_{19}$ & $\begin{array}{l}\text { "Electricity produces light and heat. The latter is locked in the bulb. So the heat sticks itself in the bulb." } \\
\text { (Casablanca) }\end{array}$ \\
\hline $\mathrm{p}_{13}$ & "It becomes hot when it accumulates a lot of electricity." (Poitiers) \\
\hline \multicolumn{2}{|c|}{ Category 5: Fuzzy, incomplete or indecipherable answer. } \\
\hline $\mathrm{n}_{40}$ & "With the energy of light and the electricity of the battery, it becomes hot." (Nova Scotia) \\
\hline $\mathrm{m}_{32}$ & $\begin{array}{l}\text { "It is because of the heat that the bulb gives off. When it remains lit too long, this is what happens. " } \\
\text { (Montreal) }\end{array}$ \\
\hline $\mathrm{c}_{20}$ & $\begin{array}{l}\text { "Because it takes energy and heats the bulb and the more it loses some, the more it is hot. However, when } \\
\text { the light will be turned off, the heat will leave because there will be no more energy that circulates. " } \\
\text { (Casablanca) }\end{array}$ \\
\hline $\mathrm{p}_{6}$ & $\begin{array}{l}\text { "If the bulb stays lit during a long time, the battery will give more power and the bulb becomes red-hot." } \\
\text { (Poitiers) }\end{array}$ \\
\hline
\end{tabular}


From the analysis of the answers it is possible to infer the following conceptions:

(1) Light is as hot as the Sun, therefore it warms up the lamp. The analogy with the sun can probably be explained by the fact that, in winter, heating is provided by using appliances that function with electricity.

(2) The electricity that passes through the filament warms it up because electricity is hot. This conception attributes the properties of heat to electricity. The terms "electricity" and "heat" are interchangeable.

(3) Electricity coming from the battery heats up the filament in the bulb and releases heat that remains in the glass bulb.

(4) Electricity produces heat that remains in the bulb and it sticks on the glass that warms up.

(5) The electricity of the battery, while going through the filament, releases heat that warms up the bulb. The battery has the electricity inside it. This conception has been highlighted in studies made in different countries of different cultures and different languages $[34 ; 36 ; 39]$.

\subsection{Categorization of the answers: Question 2}

The relative data to the question on the source of light can be classified in four categories described in table 3 .

Table 3. Categories derived from question 2

\begin{tabular}{|c|c|c|c|}
\hline Cat. & Interpretation of pupils & $\%$ & $(\mathrm{a}, \mathrm{b}, \mathrm{c}, \mathrm{d}) *$ \\
\hline $\mathrm{C}_{1}$ & $\begin{array}{c}\text { Light comes from electricity } \\
\text { stored in the battery. }\end{array}$ & 16 & $(24,5,23,12)$ \\
\hline $\mathrm{C}_{2}$ & $\begin{array}{c}\text { Light comes either from the } \\
\text { energy, either from electricity, } \\
\text { either from the liquid (hot) that } \\
\text { is in the battery. }\end{array}$ & 37 & $(37,28,20,42)$ \\
\hline $\mathrm{C}_{3}$ & $\begin{array}{c}\text { Light comes from the filament } \\
\text { of the bulb because of the } \\
\text { electricity of the battery. }\end{array}$ & 19 & $(3,37,34,21)$ \\
\hline $\mathrm{C}_{4}$ & $\begin{array}{c}\text { Fuzzy, incomplete or } \\
\text { indecipherable answer. }\end{array}$ & 28 & $(36,30,23,25)$ \\
\hline
\end{tabular}

* $(\mathrm{a}, \mathrm{b}, \mathrm{c}, \mathrm{d})$ represent the respective percentages of students from Nova Scotia $(\mathrm{N}=89)$; Montréal $(\mathrm{N}=46)$; Poitiers $(\mathrm{N}=30)$ and Casablanca $(\mathrm{N}=$ 92).

The typical answers relatively to each of these categories are reproduced fully in table 4 . The analysis of the answers gave the following conceptions:

(1) The light of the battery moves right up to the filament of the bulb that makes it shine. In this conception, the battery is considered as a source of light which comes from the battery, flows to the filament of the lamp and displays itself because of the filament.

(2) The light comes from the electricity contained in the battery.

(3) The light comes from the filament of the bulb because the electricity passes through it. This conception can be qualified as correct because the formation of light is linked to the displacement of electrical charges (electricity) in the filament.

Table 4. Answers of the pupils relatively to the question 2

\begin{tabular}{|c|c|}
\hline $\begin{array}{c}\text { Subjects' } \\
\text { codes }\end{array}$ & Advanced answers \\
\hline \multicolumn{2}{|c|}{ Category 1: Light comes from electricity stored in the battery. } \\
\hline $\mathrm{n}_{81}$ & $\begin{array}{l}\text { "Light comes from electricity kept in the battery." (Nova } \\
\text { Scotia) }\end{array}$ \\
\hline $\mathrm{m}_{42}$ & $\begin{array}{l}\text { "From the battery that gives electricity right up to the } \\
\text { bulb." (Montreal) }\end{array}$ \\
\hline $\mathrm{c}_{79}$ & $\begin{array}{l}\text { "This light comes from the battery that passes through a } \\
\text { circuit and goes in the filament that makes the lamp shine } \\
\text { and comes back to the starting point." (Casablanca) }\end{array}$ \\
\hline $\mathrm{p}_{10}$ & $\begin{array}{l}\text { "The light comes of the acid that becomes hot in the } \\
\text { battery, lets the power of heat come out, the wire carries it } \\
\text { to the bulb and voilà." (Poitiers) }\end{array}$ \\
\hline \multicolumn{2}{|c|}{$\begin{array}{l}\text { Catgory 2: Light comes either from energy, from electricity, or from } \\
\text { liquid (hot) that is in the battery. }\end{array}$} \\
\hline $\mathrm{n}_{15}$ & $\begin{array}{l}\text { "Light comes from the battery that has electricity, } \\
\text { therefore light. And electricity has no other places to go, } \\
\text { so it goes to the bulb. " (Nova Scotia) }\end{array}$ \\
\hline $\mathrm{m}_{32}$ & "From the energy of the battery." (Montreal) \\
\hline $\mathrm{c}_{45}$ & $\begin{array}{l}\text { "Light comes from the inside of the battery. The battery } \\
\text { transmits its energy for the glass bulb to light up. " } \\
\text { (Casablanca) }\end{array}$ \\
\hline $\mathrm{p}_{6}$ & $\begin{array}{l}\text { "This light comes from the battery because it is made up } \\
\text { of electricity." (Poitiers) }\end{array}$ \\
\hline \multicolumn{2}{|c|}{$\begin{array}{l}\text { Category 3: Light comes from the filament of the bulb because of the } \\
\text { electricity of the battery. }\end{array}$} \\
\hline $\mathrm{n}_{32}$ & $\begin{array}{l}\text { "The light comes from the hot electricity that turns bright } \\
\text { red and makes light in the wire." (Nova Scotia) }\end{array}$ \\
\hline $\mathrm{m}_{6}$ & $\begin{array}{l}\text { "This light comes of the electricity of the wires in the } \\
\text { bulb." (Montreal) }\end{array}$ \\
\hline$c_{32}$ & $\begin{array}{l}\text { "The light comes of the electricity that passes through the } \\
\text { wire of the bulb." (Casablanca) }\end{array}$ \\
\hline $\mathrm{p}_{20}$ & $\begin{array}{l}\text { "From electricity that reaches into the filament of the } \\
\text { bulb." (Poitiers) }\end{array}$ \\
\hline \multicolumn{2}{|c|}{ Category 4: Fuzzy, incomplete or indecipherable answer } \\
\hline $\mathrm{n}_{1}$ & $\begin{array}{l}\text { "This light comes of the battery that gives a lot of oxygen } \\
\text { that will give out light." (Nova Scotia) }\end{array}$ \\
\hline $\mathrm{m}_{4}$ & $\begin{array}{l}\text { "The bulb has two small metal wires that have a V shape } \\
\text { and there is a loop in between the } \mathrm{V} \text {, when they are joined } \\
\text { by a wire, the energy that is in the battery is going to pass } \\
\text { through the two wires and they are going to light up." } \\
\text { (Montreal) }\end{array}$ \\
\hline $\mathrm{c}_{66}$ & $\begin{array}{l}\text { "Light comes from the filament, on this filament, there is } \\
\text { electricity that will light up the lamp." (Casablanca) }\end{array}$ \\
\hline $\mathrm{p}_{7}$ & $\begin{array}{l}\text { "If }+ \text { and - meet in the small filament of the bulb, it is } \\
\text { going to make a contact like an accident (if two cars hit } \\
\text { each other, it is going to make a spark)." (Poitiers) }\end{array}$ \\
\hline
\end{tabular}

\subsection{Categorization of the answers: Question 3}

As for the relative data to question 3 which was to specify the difference between electricity and light, three categories of answers can be derived (table 5).

The typical answers relatively to each of these categories are reproduced fully in table 6 . The most widely spread conceptions are as follows:

(1) There is no any difference between light and electricity since light is produced by electricity.

(2) There is no difference between electricity and light since light is electricity.

(3) There is a difference between light and electricity since light cannot produce electricity. 
(4) There is a difference between light and electricity because the latter represents an electrical current that passes through a wire whereas light is hot and it shines.

Table 5. Categories derived from question 3

\begin{tabular}{|c|c|c|c|}
\hline $\begin{array}{c}\text { Cat } \\
.\end{array}$ & Interpretation of pupils & $\%$ & $(\mathrm{a}, \mathrm{b}, \mathrm{c}, \mathrm{d})^{*}$ \\
\hline $\mathrm{C}_{1}$ & $\begin{array}{c}\text { Electricity produces light - } \\
\text { elricity is a sort of light and light } \\
\text { (except the Sun) is a sort of } \\
\text { electricity. }\end{array}$ & 29 & $(28,37,37,29)$ \\
\hline $\mathrm{C}_{2}$ & $\begin{array}{c}\text { Electricity and light don't have the } \\
\text { same uses - light cannot produce } \\
\text { electricity and without electricity, } \\
\text { there is no light. }\end{array}$ & 25 & $(26,7,26,29)$ \\
\hline $\mathrm{C}_{3}$ & $\begin{array}{c}\text { Fuzzy, incomplete or indecipherable } \\
\text { answer. }\end{array}$ & 46 & $(48,48,37,42)$ \\
\hline
\end{tabular}

* $(\mathrm{a}, \mathrm{b}, \mathrm{c}, \mathrm{d})$ represent the respective percentages of students from Nova Scotia $(\mathrm{N}=89)$; Montréal $(\mathrm{N}=46)$; Poitiers $(\mathrm{N}=30)$ and Casablanca $(\mathrm{N}=$ 92).

Table 6. Answers of the pupils relatively to the question 3

\begin{tabular}{|c|l|}
\hline $\begin{array}{c}\text { Subjects' } \\
\text { codes }\end{array}$ & \multicolumn{1}{|c|}{ Advanced answers } \\
\hline $\begin{array}{c}\text { Category 1: Electricity produces light - electricity is a kind of light and } \\
\text { light (except the Sun) is a kind of electricity. }\end{array}$ \\
\hline $\mathrm{n}_{13}$ & $\begin{array}{l}\text { "Electricity is light. Light needs electricity." (Nova } \\
\text { Scotia) }\end{array}$ \\
\hline $\mathrm{m}_{25}$ & $\begin{array}{l}\text { "No because light is made with electricity." } \\
\text { (Montreal) }\end{array}$ \\
\hline $\mathrm{c}_{54}$ & "No because electricity is light." (Casablanca) \\
\hline $\mathrm{p}_{14}$ & $\begin{array}{l}\text { "There is no difference because light is electricity." } \\
\text { (Poitiers) }\end{array}$ \\
\hline $\begin{array}{c}\text { Category 2: Electricity and light don't have the same purpose - light } \\
\text { cannot produce electricity and, without electricity there is no light. }\end{array}$ \\
\hline $\mathrm{n}_{61}$ & $\begin{array}{l}\text { "Yes, electrical posts don't produce any light and yet } \\
\text { there is electricity." (Nova Scotia) }\end{array}$ \\
\hline $\mathrm{m}_{39}$ & $\begin{array}{l}\text { "Electricity it current that passes through a wire and } \\
\text { light is something that is hot, mixed with electricity it } \\
\text { makes light." (Montreal) }\end{array}$ \\
\hline $\mathrm{c}_{18}$ & $\begin{array}{l}\text { "Yes, with light one cannot turn on a television." } \\
\text { (Casablanca) }\end{array}$ \\
\hline $\mathrm{p}_{13}$ & $\begin{array}{l}\text { "Yes because electricity is also used for something } \\
\text { else such as in the telephone." (Poitiers) }\end{array}$ \\
\hline $\mathrm{p}_{19}$ & $\begin{array}{l}\text { "Electricity is visible whereas light is not visible." } \\
\text { (Casablanca) } \\
\text { (Because of electricity, we can produce light (with the } \\
\text { (ategory 3: Fuzzy, incomplete or indecipherable answer. }\end{array}$ \\
\hline $\mathrm{n}_{8}$ & $\begin{array}{l}\text { "No, electricity travels as quickly as light." (Nova } \\
\text { Scotia) }\end{array}$ \\
\hline "No, because light goes quickly and electricity also." \\
\hline
\end{tabular}

\subsection{Categorization of the Answers: Question 4}

The relative data to this question relates to a possible difference between electricity and heat. Three categories were found and are described in table 7.
Table 7. Categories derived from question 4

\begin{tabular}{|c|c|c|c|}
\hline Cat. & Interpretation of pupils & $\%$ & $(\mathrm{a}, \mathrm{b}, \mathrm{c}, \mathrm{d})^{*}$ \\
\hline $\mathrm{C}_{1}$ & $\begin{array}{c}\text { The heat is hot, electricity also - } \\
\text { electricity contains the heat. }\end{array}$ & 21 & $(19,20,30,22)$ \\
\hline $\mathrm{C}_{2}$ & $\begin{array}{c}\text { Electricity and the heat don't } \\
\text { have the same properties: } \\
\text { danger, light, warming up, etc. })\end{array}$ & 35 & $(30,30,23,45)$ \\
\hline $\mathrm{C}_{3}$ & $\begin{array}{c}\text { Fuzzy, incomplete or } \\
\text { indecipherable answer. }\end{array}$ & 44 & $(51,50,47,33)$ \\
\hline
\end{tabular}

$*(\mathrm{a}, \mathrm{b}, \mathrm{c}, \mathrm{d})$ represent the respective percentages of students from Nova Scotia $(\mathrm{N}=89)$; Montréal $(\mathrm{N}=46)$; Poitiers $(\mathrm{N}=30)$ and Casablanca $(\mathrm{N}=$ 92).

The typical answers relatively to each of these categories are reproduced fully in table 8 . They represent the pupil's complete explanation.

Table 8. Answers of the pupils relatively to the question 4

\begin{tabular}{|c|c|}
\hline $\begin{array}{c}\text { Subjects' } \\
\text { codes }\end{array}$ & Advanced answers \\
\hline \multicolumn{2}{|c|}{ Category 1 : Heat is hot, electricity also - electricity contains heat. } \\
\hline $\mathrm{n}_{18}$ & $\begin{array}{l}\text { "No because electricity becomes hot." (Nova } \\
\text { Scotia) }\end{array}$ \\
\hline $\mathrm{m}_{25}$ & "No because heat is part of electricity." (Montreal) \\
\hline $\mathrm{c}_{4}$ & "No because electricity is heat." (Casablanca) \\
\hline $\mathrm{p}_{5}$ & "No since electricity gives out heat." (Poitiers) \\
\hline \multicolumn{2}{|c|}{ Category 2: Electricity and heat do not have the same properties. } \\
\hline $\mathrm{n}_{16}$ & $\begin{array}{l}\text { "Yes, heat can be made of wood but not electricity." } \\
\text { (Nova Scotia) }\end{array}$ \\
\hline $\mathrm{m}_{39}$ & $\begin{array}{l}\text { "Electricity is the current that passes through a wire } \\
\text { and heat is something that is hot like a bulb." } \\
\text { (Montreal) }\end{array}$ \\
\hline$c_{91}$ & $\begin{array}{l}\text { "Electricity is used to light up something whereas } \\
\text { heat is used to heat something." (Casablanca) }\end{array}$ \\
\hline $\mathrm{p}_{10}$ & $\begin{array}{l}\text { "Yes because electricity electrocutes you and heat } \\
\text { burns you." (Poitiers) }\end{array}$ \\
\hline \multicolumn{2}{|c|}{ Category 3: Fuzzy, incomplete or indecipherable answer. } \\
\hline $\mathrm{n}_{44}$ & $\begin{array}{l}\text { "Yes, fire is not made of a source of energy." (Nova } \\
\text { Scotia) }\end{array}$ \\
\hline $\mathrm{m}_{44}$ & $\begin{array}{l}\text { "Heat is hot, electricity is not hot but it becomes hot } \\
\text { as soon as it touches a conductor." (Montreal) }\end{array}$ \\
\hline $\mathrm{c}_{38}$ & "Electricity is made of small wires." (Casablanca) \\
\hline $\mathrm{p}_{13}$ & $\begin{array}{l}\text { "A little bit because there are the radiators that do } \\
\text { not function with electricity." (Poitiers) }\end{array}$ \\
\hline
\end{tabular}

The identified conceptions are as follows:

(1) There is no difference between electricity and heat since (a) the heat is produced by electricity and (b) electricity can also give heat.

(2) There is a difference between heat and electricity since (a) with heat one cannot operate devices such as a television, (b) the heat is hotter than electricity, (c) with wood one can have heat but, not electricity and (d) electricity can kill whereas with heat, it is rare.

5.5. Categorization of the Answers: Question 5

The relative data to this question on the composition of a battery revealed five categories described in table 9 . 
Table 9. Categories derived from question 5

\begin{tabular}{|c|c|c|c|}
\hline Cat. & Interpretation of pupils & $\%$ & $(\mathrm{a}, \mathrm{b}, \mathrm{c}, \mathrm{d})^{*}$ \\
\hline $\mathrm{C}_{1}$ & $\begin{array}{c}\text { There is electricity and wires } \\
\text { in a battery. }\end{array}$ & 21 & $(21,17,13,30)$ \\
\hline $\mathrm{C}_{2}$ & $\begin{array}{c}\text { There is either liquid acid, } \\
\text { either mercury, either oil, } \\
\text { either a gas, either a chemical } \\
\text { that releases or retains } \\
\text { electricity in a battery. }\end{array}$ & 29 & $(45,35,10,11)$ \\
\hline $\mathrm{C}_{3}$ & $\begin{array}{c}\text { There is either energy, either a } \\
\text { force, either volts in a battery. }\end{array}$ & 12 & $(8,13,13,18)$ \\
\hline $\mathrm{C}_{4}$ & $\begin{array}{c}\text { There are only wires in a } \\
\text { battery. }\end{array}$ & 9 & $(7,7,20,9)$ \\
\hline $\mathrm{C}_{5}$ & $\begin{array}{c}\text { Fuzzy, incomplete or } \\
\text { indecipherable answer. }\end{array}$ & 29 & $(19,28,44,32)$ \\
\hline
\end{tabular}

*(a, b, c, d) represent the respective percentages of students from Nova Scotia $(\mathrm{N}=89)$; Montréal $(\mathrm{N}=46)$; Poitiers $(\mathrm{N}=30)$ and Casablanca $(\mathrm{N}=92)$.

The typical answers relatively to each of these categories are reproduced fully in table 10 . The most widely spread conception is that a battery is made of wires and electricity.

Table 10. Answers of the pupils relatively to the question 5

\begin{tabular}{|c|c|}
\hline $\begin{array}{c}\text { Subjects' } \\
\text { codes }\end{array}$ & Advanced answers \\
\hline \multicolumn{2}{|c|}{ Category 1: There is electricity and wires in a battery. } \\
\hline $\mathrm{n}_{13}$ & $\begin{array}{l}\text { "I think that there are small wires and electricity in the } \\
\text { batteries." (Nova Scotia) }\end{array}$ \\
\hline $\mathrm{m}_{26}$ & $\begin{array}{l}\text { "Inside a battery there is electricity, it is the reason for } \\
\text { making light nevertheless strong." (Montreal) }\end{array}$ \\
\hline $\mathrm{c}_{34}$ & $\begin{array}{l}\text { "There is electricity in it and also wires are in it." } \\
\text { (Casablanca) }\end{array}$ \\
\hline $\mathrm{p}_{21}$ & "Wires and electricity." (Poitiers) \\
\hline \multicolumn{2}{|c|}{$\begin{array}{l}\text { Category 2: There is either liquid acid, mercury, oil, a gas, or a chemical } \\
\text { that releases or retains electricity in a battery. }\end{array}$} \\
\hline $\mathrm{n}_{16}$ & $\begin{array}{l}\text { "Inside a battery there is a liquid (poison) that can make } \\
\text { electricity for a little while." (Nova Scotia) }\end{array}$ \\
\hline $\mathrm{m}_{21}$ & "Gas to create light." (Montreal) \\
\hline $\mathrm{c}_{64}$ & "Harmful acid." (Casablanca) \\
\hline $\mathrm{p}_{10}$ & "A liquid that contains electricity." (Poitiers) \\
\hline \multicolumn{2}{|c|}{ Category 3: There is either energy, a force or volts in a battery. } \\
\hline $\mathrm{n}_{10}$ & "There are wires and liquid." (Nova Scotia) \\
\hline $\mathrm{m}_{39}$ & $\begin{array}{l}\text { "In the battery, there is the current, energy, coal and oil." } \\
\text { (Montreal) }\end{array}$ \\
\hline $\mathrm{c}_{9}$ & "Mercury, a source of energy." (Casablanca) \\
\hline $\mathrm{p}_{30}$ & $\begin{array}{l}\text { "Inside a battery, a part is formed of energy and another } \\
\text { part of metal so that electricity can pass." (Poitiers) }\end{array}$ \\
\hline \multicolumn{2}{|c|}{ Category 4: There are only some wires in a battery. } \\
\hline$\overline{\mathrm{n}_{19}}$ & "There are thousands of electrons." (Nova Scotia) \\
\hline $\mathrm{m}_{2}$ & $\begin{array}{l}\text { "Wires that operate the battery and that could operate } \\
\text { electric things." (Montreal) }\end{array}$ \\
\hline $\mathrm{c}_{20}$ & "There is a toxic liquid and electric wire." (Casablanca) \\
\hline $\mathrm{p}_{6}$ & $\begin{array}{l}\text { "Wires, electricity, thick white water (creamy) unfit to } \\
\text { drink." (Poitiers) }\end{array}$ \\
\hline \multicolumn{2}{|c|}{ Category 5: Fuzzy, incomplete or indecipherable answer. } \\
\hline $\mathrm{n}_{15}$ & $\begin{array}{l}\text { "There is energy in a battery because if you put two } \\
\text { batteries together, the energy goes into the other." (Nova } \\
\text { Scotia) }\end{array}$ \\
\hline $\mathrm{m}_{10}$ & "Electric wires, iron, plates." (Montreal) \\
\hline $\mathrm{c}_{8}$ & "Energy and a battery." (Casablanca) \\
\hline $\mathrm{p}_{13}$ & $\begin{array}{l}\text { "In my opinion there is a battery and aluminum." } \\
\text { (Poitiers) }\end{array}$ \\
\hline
\end{tabular}

\subsection{Categorization of the Answers: Question 6}

The relative data to the question on what is electricity is categorized in table 11 .

Table 11. Categories derived from question 6

\begin{tabular}{|c|c|c|c|}
\hline Cat. & Interpretation & $\%$ & $(\mathrm{a}, \mathrm{b}, \mathrm{c}, \mathrm{d})^{*}$ \\
\hline $\mathrm{C}_{1}$ & Associates electricity to light. & 15 & $(31,17,10,10)$ \\
\hline $\mathrm{C}_{2}$ & $\begin{array}{c}\text { Evokes the utilitarian aspect of } \\
\text { electricity. }\end{array}$ & 22 & $(32,24,10,12)$ \\
\hline $\mathrm{C}_{3}$ & $\begin{array}{c}\text { Evokes the dangerous aspect of } \\
\text { electricity. }\end{array}$ & 6 & $(2,11,7,6)$ \\
\hline $\mathrm{C}_{4}$ & $\begin{array}{c}\text { Evokes the notion either of } \\
\text { energy, either of electrical } \\
\text { current, either of force, either } \\
\text { of power. }\end{array}$ & 35 & $(25,13,40,49)$ \\
\hline $\mathrm{C}_{5}$ & $\begin{array}{c}\text { Fuzzy, incomplete or } \\
\text { indecipherable answer. }\end{array}$ & 22 & $(10,35,33,24)$ \\
\hline
\end{tabular}

$*(a, b, c, d)$ represent the respective percentages of students from Nova Scotia $(\mathrm{N}=89)$; Montréal $(\mathrm{N}=46)$; Poitiers $(\mathrm{N}=30)$ and Casablanca $(\mathrm{N}=92)$.

Table 12. Answers of the pupils relatively to the question 6

\begin{tabular}{|c|c|}
\hline $\begin{array}{l}\text { Subjects' } \\
\text { codes }\end{array}$ & Advanced answers \\
\hline \multicolumn{2}{|c|}{ Category 1: Associates electricity to light. } \\
\hline $\mathrm{N}_{17}$ & "It is light and nintendo and television." (Nova Scotia) \\
\hline $\mathrm{m}_{16}$ & "Electricity is light and heat from a stove." (Montreal) \\
\hline $\mathrm{c}_{34}$ & "Light and fire." (Casablanca) \\
\hline $\mathrm{p}_{6}$ & "It is current, light, etc. " (Poitiers) \\
\hline \multicolumn{2}{|c|}{ Category 2: Evokes the utility aspect of electricity. } \\
\hline $\mathrm{n}_{14}$ & $\begin{array}{l}\text { "I like electricity because you cannot watch television if } \\
\text { there is no electricity." (Nova Scotia) }\end{array}$ \\
\hline $\mathrm{m}_{21}$ & $\begin{array}{l}\text { "It is something very important. Examples, the telephone, } \\
\text { the television, the hot water, light, the radio. " (Montreal) }\end{array}$ \\
\hline $\mathrm{c}_{62}$ & "A means to illuminate us." (Casablanca) \\
\hline $\mathrm{p}_{16}$ & $\begin{array}{l}\text { "For me it is what makes all things functioning such as the } \\
\text { television, light, etc." (Poitiers) }\end{array}$ \\
\hline \multicolumn{2}{|c|}{ Category 3: Evokes the dangerous aspect of electricity. } \\
\hline $\mathrm{N}_{64}$ & $\begin{array}{l}\text { "Electricity is a phenomenon that helps some things to } \\
\text { function but that can kill people." (Nova Scotia) }\end{array}$ \\
\hline $\mathrm{m}_{9}$ & $\begin{array}{l}\text { "A current that makes light move and it is something } \\
\text { dangerous." (Montreal) }\end{array}$ \\
\hline $\mathrm{c}_{12}$ & $\begin{array}{l}\text { "Electricity is very dangerous for human beings." } \\
\text { (Casablanca) }\end{array}$ \\
\hline $\mathrm{p}_{20}$ & $\begin{array}{l}\text { "It is very dangerous and at the same time practical." } \\
\text { (Poitiers) }\end{array}$ \\
\hline
\end{tabular}

Category 4: Evokes the notion of energy, electric current, force, or power.

\begin{tabular}{|c|l|}
\hline $\mathrm{n}_{12}$ & $\begin{array}{l}\text { "Electricity isenergy that makes things light up and } \\
\text { function." (Nova Scotia) }\end{array}$ \\
\hline $\mathrm{m}_{39}$ & $\begin{array}{l}\text { "It is energy that passes through a wire or a bulb." } \\
\text { (Montreal) }\end{array}$ \\
\hline $\mathrm{c}_{63}$ & $\begin{array}{l}\text { "Energy that circulates in a continuous and closed circuit." } \\
\text { (Casablanca) }\end{array}$ \\
\hline $\mathrm{p}_{22}$ & $\begin{array}{l}\text { "It is an energy that is used to light up electric devices." } \\
\text { (Poitiers) }\end{array}$ \\
\hline Category 5: Fuzzy, incomplete or indecipherable answer \\
\hline $\mathrm{n}_{8}$ & "A big flashlight." (Nova Scotia) \\
\hline $\mathrm{m}_{30}$ & "For me, electricity is life." (Montreal) \\
\hline $\mathrm{c}_{26}$ & $\begin{array}{l}\text { "Electricity for me is water mixed with gas and all sorts of } \\
\text { chemicals." (Casablanca) }\end{array}$ \\
\hline $\mathrm{p}_{2}$ & $\begin{array}{l}\text { "It is gas mixed with toxic things that becomes like little } \\
\text { strikes of lightning." (Poitiers) }\end{array}$ \\
\hline
\end{tabular}


The few typical answers relatively to each of the categories are reproduced fully in table 12. The conceptions about electricity are linked either to its utilitarian aspect (telephone, television, hot water, light, etc.) or its dangerous aspect. Also, several pupils associate electricity to energy, without elaborating on what is energy. This reference probably relates to their common language in which one often uses the expressions "electrical energy" and "power energy".

\section{Interpretation of Results}

The thesis of the "ethnocentricity" of the conceptions about scientific concepts does not seem to find support in this exploratory study on the scientific concept of the transformations of energy in a simple electric circuit among pupils of three different countries. It is rather the thesis of the "universality" that is here reinforced. The interpretation that one can make of this study is to take into account the subject studied and the cultural environment in which these conceptions have been collected. On one hand, the technical object that is represented by a simple electric circuit is a device with international symbols (signs + and - on the poles of a battery), a bulb with a filament inside linked to its poles, and connecting electric wires. On the other hand, the majority of the pupils who participated in this study live in an urban or rural environment inside countries whose technological level make it possible for them to access theses aspects of the material culture.

However the question of the universality or the ethnocentricity of the conceptions remains an open question because pupils of different cultures interpret scientific concepts differently $[21 ; 23 ; 1]$. Therefore, it appears important to continue to seek the conceptions of the pupils of different cultures about scientific concepts if we are to become knowledgeable about the whole range of the conceptual schemas of these concepts that pupils have in the classes of sciences. Also, the results demonstrate that there is only a minority of pupils who has some conceptions in continuity with the scientific concepts related to the transformations of energy within a simple electric circuit. Therefore, there are some advantages to begin the instruction with identifying the previous conceptions of the pupils, mobilizing them, and offering learning situations that encourages them to put their conceptions to the test in scientific activities. In a multicultural environment, one can glimpse what can happen when some pupils share the same conceptions. On the one hand, the communication between them becomes a lot easier. On the other hand, the teacher can begin teaching with a similar starting point for all. What's more, one notes that many developing countries have often programs of sciences that come from countries and cultures different from theirs. Vigilance is needed to consider the manner to present the scientific notions contained in such programs. Indeed, the phenomena presented could lead to connotations very different from those of the science program in the country of origin.

\section{Conclusions}

It is generally accepted in the field of the didactic of sciences that the learning of scientific notions is a long and rigorous one. However for Bachelard [28], the head of a pupil that begins this learning is never empty, although some parts can be "filled" with big ideas that have ties and reductions manufactured to order. Also, a teacher's role is not to fill emptiness, but to help the pupil to sort out and rectify his ideas [20]. His role is also to look for the revealing indications for him to give leads that will feed the curiosity of the pupils. In this perspective, the study of the conceptions about scientific concepts on the question of universality or ethnocentricity is thought to be a tool to facilitate the work of the teachers of sciences in the elementary and secondary levels. If this study reveals universality in the conceptions about energy transformations of a simple electric circuit, it suggests nevertheless continuing the work in order to try to understand the divergences in the results of previous research on this question. In another way, such work serves to bring more to light on the manner by which pupils perceive phenomena of scientific order and especially on the manner in which their own explanations depart from those that adults often expect. It would be advantageous for a teacher who works in a multicultural context to know the conceptions which are shared by his pupils and those which are not. This question of universality and ethnocentricity is relevant in the case of classes in which there are children of different origins and cultures. It is also relevant in the context of the globalization of scientific knowledge. Thus, the knowledge by the teacher of universal conceptions will encourage interaction between pupils of different cultures by showing them that, in spite of their differences, they share similar conceptions on certain notions as it was shown in this study on the transformations of chemical, electrical, light, and thermal energy in a simple electrical circuit. In a teaching context, it would be important that pupils know that their naive conceptions on notions of heat, light and electrical current were shared in history by many scientists of different cultures. In the case of ethnocentricity, a debate among pupils could be interesting and would enrich their general culture especially when considering their language and culture of origin.

\section{Acknowledgements}

We are very grateful to the pupils and their teachers for their participation and to Gordon MacWillie for his help with the English language. 


\section{REFERENCES}

[1] M. McCloskey. 1983. Naïve theories of motion. In D. Gentner \& A.L. Stevens (Eds.), Mental models (pp. 299-324, Hillsdale, NJ: Lawrence Erlbaum Associates, Inc.

[2] L. Viennot. 1979. "Spontaneous reasoning in elementary dynamics". European Journal of Science Education, 1, pp. 205-221.

[3] J.G. Sharp. 1996. "Children's astronomical beliefs: a preliminary study of Year 6 children in south-west England". International Journal of science education, 18(6), pp. 685-712.

[4] S. Vosniadou. 1990. "Cross-cultural investigation of children's conceptions about the earth, the sun and the moon: Greek and American data". Available from: https://www.ideals.illinois.edu/bitstream/handle/2142/17930/ ctrstreadtechrepv01990i00497_opt.pdf?sequence=1

[5] A. Métioui, M. Baulu MacWillie. 2013. "Children's Beliefs about the Concepts of Distance, Time and Speed". International Journal of Education, Learning and Development, 1(2), pp. 24-38.

[6] J. Piaget. (1970). The child's conception of movement and speed. London: Routledge \& Kegan Paul.

[7] Z. Zhou, T.-S. Peverly, E.-A. Boehm, L. Chongdec. 2000. "American and Chinese children's understanding of distance, time, and speed interrelations". Cognitive Development, $15(2)$, pp. 215-240.

[8] A. Fetherstonhaugh, J. Happs, D. Treagust. 1987. "Students' misconceptions about light: a comparative study of prevalent views found in Western Australia, France, New Zealand, Sweden and the United States". Research in Science Education, 17, pp. 156-64.

[9] B. Anderson, C. Karrqvist. 1983. "How Swedish pupils, aged 12-15 years, Understand light and its properties". European Journal of Science Education, 5, pp. 4-38.

[10] H.E. Chu, D.F. Treagust, A.L. Chandrasegaran. 2009. “A stratified study of students' understanding of basic optics concepts in different contexts using two-tier multiple-choice items". Research in Science \& Technological Education, 27(3), pp. 253-265.

[11] G. L. Erickson. (1980). Children's viewpoint of heat: A second look. Science Education, 64, pp. 323-336.

[12] G. L. Erickson, A. Tiberghien. 1985. Heat and temperature. In R. Driver, E, Guesne, \& A. Tiberghien (Eds.), Children's ideas in science (pp. 52-84). Philadelphia: Open University Press.

[13] H.E. Chu, D.F. Treagust, S. Yeo, M. Zadnik. 2012. Evaluation of Students' Understanding of Thermal Concepts in Everyday Contexts. International Journal of Science Education, 34(10), pp. 1509-1534.

[14] G. Erickson, A. Tiberghien. 1985. Heat and temprature. In Chidren's Ideas in Science, R, Driver, E, Guesne \& A, Tiberghien (Eds.). Open University Press: Milton Keynes, England, pp. 52-84.

[15] R. Maskill, A. F. C. Cachapuz, V. Koulaidis. 1997. "Young pupil's ideas about the microscopic nature of matter in three different European countries". International Journal of
Science Education, 19(6), pp. 631-645.

[16] P. Lynch. 1996. 'Students' alternative frameworks for the nature of matter: a cross cultural study of linguistic and cultural interpretation". International Journal of Science Education, 18(6), 743-754.

[17] J. Piaget, B. Inhelder. (1974). The child's construction of quantities: Conservation and atomism (A.J, Pomerans, Trans.). London: Routledge \& Kegan Paul.

[18] M. Reiner, J.D. Slotta, Michelene T.H. Chi, L.B. Resnick. 2000. "Naïve Physics reasoning: A Commitment to Substance-Based Conceptions". Cognition and Instruction, 18(1), p. 1-34.

[19] T.K. Au. (1994). "Developing an intuitive understanding of conservation kinds". Cognitive Psychology, 27(1), pp. 71-111.

[20] R.J. Osborne, B.W. Schollmum. (1983). "Coping with chemistry". Australian Science Teacher Journal, 29(1), pp. 13-24.

[21] J. Lowe. (1997). "Scientific concept development in Solomon Islands students: A comparative analysis". International Journal of Science Education, 19(7), p. 743-759.

[22] A. Solomon Chiromo. 2001. Zimbabwean students' conceptions of selected ecological concepts". African Journal of Research in Mathematics, Science and Technology, 5, p. 85-98.

[23] G.M. Sinatra, S.A. Southerland, F. McConaughy, J.W. Demastes. 2003. "Intentions and beliefs in students' understanding and acceptance of biological evolution". Journal of Research in Science Teaching, 40, 510-528.

[24] R.J. Reiss. (2009). "The relationship between evolutionary biology and religion." Evolution, 63, 1934-1941.

[25] K, Taryn, M. Sanders. 2013. "Use of Confidence Scales in Analysing Unscientific Ideas about Evolution among Religious Jewish Students". African Journal of Research in Mathematics, Science and Technology Education, 17 (1), p. $2-38$.

[26] A. Tiberghien. 2003. Des connaissances naïves au savoir scientifique. In M. Kail \& M. Fayol (Eds.), Les sciences cognitives et l'école. La question des apprentissages, pp. 333-443, Paris : Presses Universitaires de France.

[27] E. Gaigher. 2014. Questions about Answers: Probing Teachers' Awareness and Planned Remediation of Learners' Misconceptions about Electric Circuits. African Journal of Research in Mathematics, Science and Technology Education, 18 (2), pp. 176-187.

[28] G. Bachelard. 1980. La formation de l'esprit scientifique. Paris : Librairie philosophique J. Vrin.

[29] N. Gough, K. Kessen. 1992. "Body and narrative as cultural test. Toward a curriculum of continuity and connection". Paper presented at the annual meeting of the American Educational Research Association, San Francisco, CA.

[30] M. Ogawa. 1995. "Science education in a multi-science perspective". Science Education, 79, pp. 593-593.

[31] G. Snively. 1990. "Traditional Native Indian beliefs, cultural values, and science instruction". Canadian Journal of Native Education, 17, PP. 44-59. 
[32] D. F. Treagust, R. Duit. 2009. "Multiple Perspectives of Conceptual Change in Science and the Challenges Ahead". Journal of Science and Mathematics Education in Southeast Asia, 32(2), pp. 89-104.

[33] D. M. Shipstone, W. Jung, J.-J. Dupin. 1998. “A study of students' understanding of electricity in five European countries". International Journal of Science Education, 10(3), pp. 303-316.

[34] J. Mackay, P. Hobden. 2012. "Using circuit and wiring diagrams to identify students' preconceived ideas about basic electric circuits". African Journal of Research in MST Education, 16(2), pp. 131-144.

[35] A. Métioui, C. Brassard, J. Levasseur, M. Lavoie. 1996. “The persistence of students' unfounded beliefs about electrical circuits: the case of Ohm's law". International Journal of
Science Education, 18(2), pp. 193-212.

[36] M. Jabot, D. Henry. 2007. "Mental Models of Elementary and Middle School Students in Analyzing Simple Battery and Bulb Circuits", School Science and Mathematics, 107(1), pp. 371-381.

[37] P. Webb. (1992). "Primary science teachers' understanding of electric current". International Journal of Science Education, 14(4), pp. 423-429.

[38] S. Çepni, E. Keles. 2006. “Turkish students' conceptions about the simple electric circuits". International Journal of Science and Mathematics Education, 4, pp. 269-291.

[39] R.J. Osborne. (1982). “Investigating Chidren's Ideas about Electric Current Using an Interview-About-Instances Procedure". Hamilton, New Zealand, SERU, University of Waikito. 